Case Report

\title{
Laryngeal Giant Cell Tumor: A Case Report and Review of the Literature
}

\author{
Jumpei Nota, Yoshihisa Okochi, Futoshi Watanabe, and Tadahiko Saiki \\ Department of Otorhinolaryngology, Steel Memorial Hirohata Hospital, 3-1 Yumesaki-cho, Hirohata-ku, Himeji-shi, \\ Hyogo 671-1122, Japan \\ Correspondence should be addressed to Jumpei Nota; nouta313@gmail.com
}

Received 2 February 2014; Accepted 2 May 2014; Published 15 May 2014

Academic Editor: Andrea Gallo

Copyright (c) 2014 Jumpei Nota et al. This is an open access article distributed under the Creative Commons Attribution License, which permits unrestricted use, distribution, and reproduction in any medium, provided the original work is properly cited.

\begin{abstract}
Giant cell tumor (GCT) is a benign neoplasm arising most commonly in the long bones. GCTs of the larynx (GCTL) are relatively rare, and only individual case reports are documented in the literature. Patients with such tumors may present with hoarseness and anterior neck swelling. We present a 59-year-old man with hoarseness and enlarging anterior neck mass for 3 months. A fiberscopy revealed a submucosal swelling of the left subglottic trachea. Computed tomography and magnetic resonance imaging of the larynx demonstrated a large, well-defined, inhomogeneous enhancing mass at the left thyroid cartilage, which was obstructed entirely. The anterior neck mass was biopsied for histopathological analysis, which showed multinodularity with intervening vascularized connective tissues. The mass was made up of mononuclear cells and distributed multinucleated giant cells. The mitotic activity of the mononuclear cells was as high as 6 per 10 high-power fields. Pathologic consultation resulted in a diagnosis of giant cell tumor. The patient underwent total laryngectomy and, postoperatively, he did well without recurrence or metastasis for two and a half years.
\end{abstract}

\section{Introduction}

Giant cell tumor (GCT) is classified as a benign bone tumor, and it represents 4 to $9.5 \%$ of all bone tumors and $20 \%$ of all benign bone tumors [1]. It occurs in 20 - to 45 -year-old individuals, with a slightly higher predominance in women [2]. The tumor is frequently identified at the distal femur, proximal tibia, distal radius, proximal humerus, and sacrum [3]. Primary giant cell tumors of the larynx (GCTL) are very rare. Our review of the literature discovered 31 cases of GCTL reported since Wessely presented the first case in 1940 [4]. Herein, we report a new case of GCTL and present a concise review of the literature.

\section{Case Presentation}

A 59-year-old man was referred to our department with a 3-month history of gradually worsening hoarseness and enlarging anterior neck mass. On physical examination, a firm and fixed mass measuring $3.0 \mathrm{~cm}$ at its maximum diameter was noted in the left region of the thyroid. Endoscopic examination revealed a submucosal swelling of his left vocal fold with intact movement. The laryngeal mucosa did not appear to have an ulcerative or hemorrhagic lesion (Figure 1). A computed tomography (CT) scan of his larynx showed cortical expansion and destruction at the left side of the thyroid cartilage. Magnetic resonance imaging (MRI) revealed the same findings as CT scanning: a low-intensity area on T1-weighted images (Figure 2(a)) and a nonhomogenous high-intensity area on T2-weighted images (Figure 2(b)). The images of the tumor demonstrated high intensity on a postgadolinium contrast T1 image (Figure 2(c)). Histopathological findings obtained by incisional biopsy supported a diagnosis of giant cell tumor. We performed total laryngectomy because the tumor involved more than half of the thyroid cartilage and cricoid. The surgical resected specimen, measuring $3.0 \mathrm{~cm}$, showed an unencapsulated solid white and gray mass and was located under the intact mucosa. It destroyed the posterior lamina of the thyroid cartilage, but the anterior lamina was intact. The interface between the tumor and the adjacent mucosa and the cartilage was clearly delineated (Figure 3). Histological examination revealed a cellular mononuclear eosinophilic stromal component, and multinucleated osteoclast-like giant cells were 
TABLE 1: Summary of reported cases of GCT of the larynx.

\begin{tabular}{|c|c|c|c|c|c|}
\hline Case & Age & Sex & Location & Treatment & Follow-up \\
\hline Wessely [4] & 51 & Male & Cricoid & $\mathrm{RT}$ & \\
\hline Federova [7] & 35 & Male & Thyroid & Partial laryngectomy $+\mathrm{RT}$ & NED $1 \mathrm{y}$ \\
\hline Wagemann [8] & 40 & Male & Cricothyroid & Laryngectomy + RT & NED $7 y$ \\
\hline Perrino [9] & 32 & Male & Cricoid & Laryngofissure + RT & NED $0.25 y$ \\
\hline Kaliteevskii and Korol'kova [10] & 52 & Male & Thyroid & Laryngectomy & \\
\hline Pohl [11] & 50 & Male & Thyroid & $\mathrm{RT}$ & NED $2 y$ \\
\hline Kohn [12] & 50 & Male & Epiglottis & NA & \\
\hline Rudert [13] & 53 & Male & Thyroid & Partial laryngectomy & NED $8 y$ \\
\hline Hall-Jones [14] & 26 & Male & Thyroid & Laryngectomy & NED $1.5 \mathrm{y}$ \\
\hline Goto and Nakashima [15] & 47 & Male & Thyroid & Partial laryngectomy & \\
\hline Kotarba and Niezabitowski [16] & 60 & Male & Epiglottis & Partial laryngectomy & NED $0.5 \mathrm{y}$ \\
\hline Ribari et al. [17] & 35 & Male & Cricoid & Laryngectomy + RT & NED $6 y$ \\
\hline Kubo et al. [18] & 40 & Male & Cricoid & Laryngofissure +5 -Fluorouracil + RT & \\
\hline Tsybyme and Bogdanskaia [19] & 34 & Male & Thyroid & Laryngofissure + RT & \\
\hline Borghese et al. [20] & 28 & Male & Thyroid & Laryngofissure & NED $1.25 y$ \\
\hline Badet et al. [21] & 23 & Female & NA & NA & \\
\hline Murrell and Lantz [22] & 42 & Male & Thyroid & Laryngectomy + neck dissection & \\
\hline Martin et al. [23] & 23 & Male & Thyroid & Partial laryngectomy & NED $5 y$ \\
\hline Miyata et al. [24] & 60 & Male & Thyroid & Laryngectomy & \\
\hline Werner et al. [25] & 35 & Male & Thyroid & Laryngectomy & NED $7.5 y$ \\
\hline Hinni [26] & 31 & Male & Thyroid & Partial laryngectomy & NED $3 y$ \\
\hline Wieneke et al. [27] & 44 & Male & Thyroid & Laryngectomy & NED $0.6 \mathrm{y}$ \\
\hline Wieneke et al. [27] & 57 & Male & Cricoid & RT & NED $1.6 \mathrm{y}$ \\
\hline Wieneke et al. [27] & 37 & Male & Cricoid & Partial laryngectomy & NED $13.9 \mathrm{y}$ \\
\hline Wieneke et al. [27] & 40 & Male & Thyroid & Partial laryngectomy & \\
\hline Wieneke et al. [27] & 53 & Female & Thyroid & Partial laryngectomy & NED $16.9 y$ \\
\hline Wieneke et al. [27] & 62 & Female & Thyroid & Laryngectomy & NED $24.9 y$ \\
\hline Wieneke et al. [27] & 26 & Male & Thyroid & Laryngectomy & NED $1.5 \mathrm{y}$ \\
\hline Wieneke et al. [27] & 37 & Male & Thyroid & RT + cyclophosphamide & NED 19.4 y \\
\hline Wong and Seikaly [28] & 49 & Male & Thyroid & Partial laryngectomy & NED $2.7 \mathrm{y}$ \\
\hline Nishimura et al. [29] & 31 & Male & Thyroid & Partial laryngectomy & NED $0.7 \mathrm{y}$ \\
\hline Coyas et al. [30] & 67 & Male & Vocal cord & Laryngofissure + RT & NED $1 y$ \\
\hline Present case & 59 & Male & Thyroid & Laryngectomy & NED $2.5 \mathrm{y}$ \\
\hline
\end{tabular}

NA: not available; NED: no evidence of disease; and RT: radiation therapy.

scattered throughout the lesion in an intermediate power field (Figure 4(a)). Pleomorphic giant cells were absent. Mitotic figures were about $6 / 10 \mathrm{HPF}$ by the lack of cytological atypia (Figure 4(b)). Histopathological findings yielded a diagnosis of "giant cell tumor with local invasion." The patient has been well following total laryngectomy and subsequently free of disease for two and a half years.

\section{Discussion}

Giant cell tumors (GCTs) are relatively frequent skeletal tumors that occur mainly at the distal end of the femur and the proximal end of the tibia. In the head and neck region, GCTs are found mainly in the maxillary region [5] and at the base of the skull [6]. GCTs rarely arise from the cartilaginous laryngeal skeleton. The first case was published by Wessely in

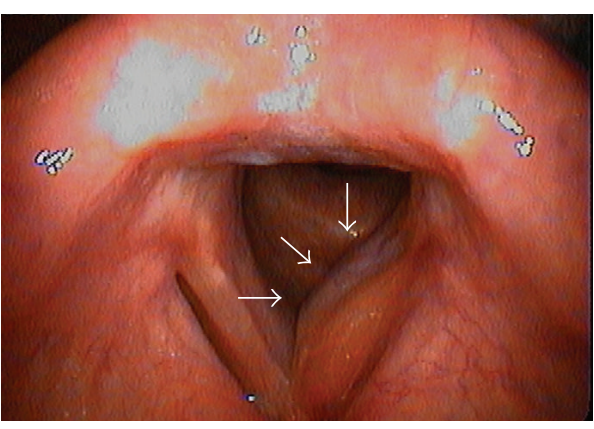

Figure 1: A submucosal swelling of the left subglottic trachea (arrow) by fiberscopic examination.

1940 [4] and, after that study, a review of the literature uncovered 31 cases of GCTL $([4,7-30]$, Table 1$)$. Nishimura et al. 


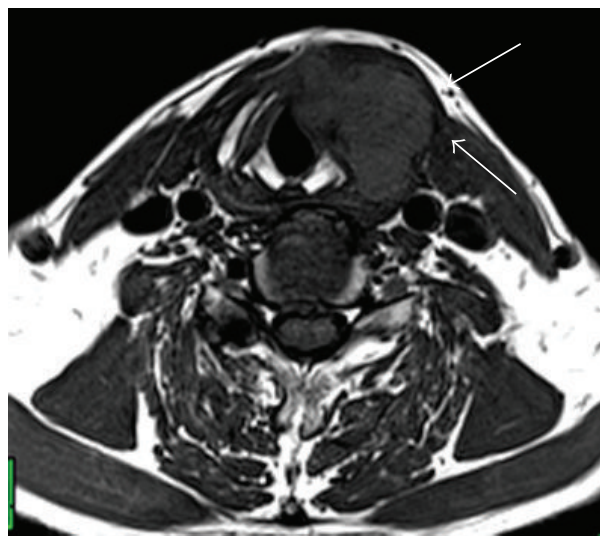

(a)

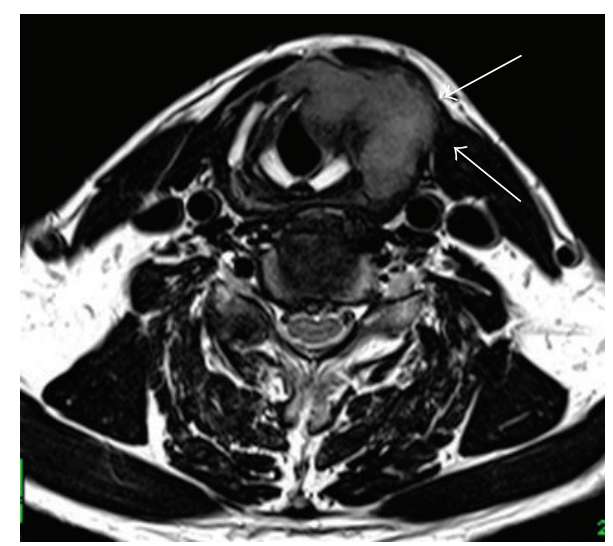

(b)

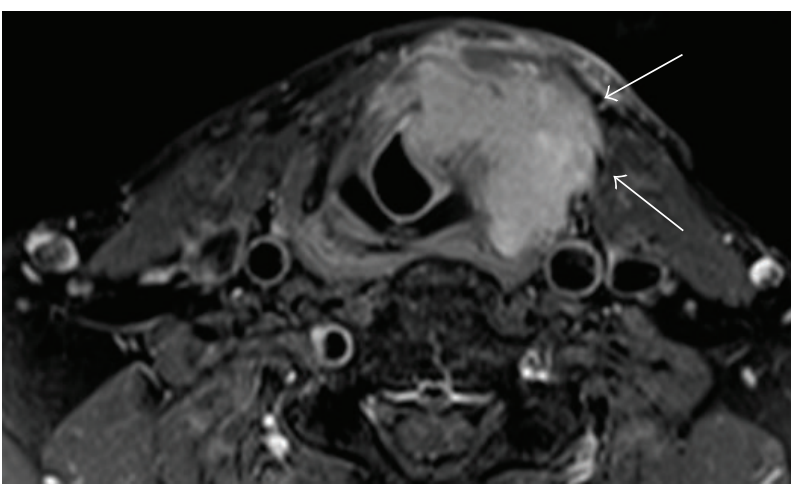

(c)

FIgURE 2: MRI revealed the same findings as CT scanning: (a) a low-intensity area on T1-weighted images and (b) a nonhomogenous highintensity area on T2-weighted images. (c) The tumor demonstrates high intensity on a postgadolinium contrast T1 image (arrow).

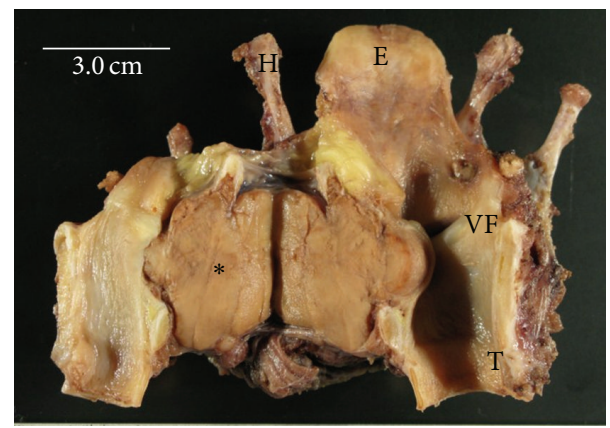

FIGURE 3: From behind, the laryngectomy specimen reveals a giant cell tumor under the intact mucosa (*). E: epiglottis, $\mathrm{H}$ : hyoid bone, T: trachea, VF: vocal fold, and scale bar $=3.0 \mathrm{~cm}$.

reported [29] that the age at presentation averaged 41.7 years and ranged from 23 to 60 years. The male/female ratio was $9: 1$, whereas GCT of the bone is more frequent in women. The most typical clinical presentation, hoarseness and then anterior neck mass, does not differ substantially from that of other laryngeal malignancies. Radiologic investigations do not usually aid in differentiating GCT of the larynx from other neoplasms, so the diagnosis of GCT is established with an open biopsy.
The common head and neck sites for these tumors correspond to the cranial bones formed by endochondral ossification. The laryngeal skeleton is primarily composed of hyaline cartilage until approximately the second decade of life, at which time it may gradually begin to be replaced by bone. This occurs at different rates in different individuals but occurs earlier in males [26].

The treatment of GCTs is controversial, and no consensus exists on their management. A review of the literature reveals that the majority of patients were managed surgically (Table 1). Surgical excision of the tumor yielded excellent outcomes, but drawbacks include complications with voice quality. Bell et al. [31] advise radiotherapy. In this context, Rudert [13] has pointed out that a large proportion of radioinduced sarcomas were GCT of the bone, treated primarily with radiotherapy. It is difficult to estimate the risk of inducing a postirradiation sarcoma in GCT because of the small number of cases described in the literature. Radiation has been used as an adjuvant treatment in some cases, but the general consensus is that it is not needed and does not significantly affect outcome.

GCT of the bone is a locally osteolytic tumor with variable aggressiveness. In rare cases, pulmonary metastasis can be observed [32]. Additionally, Coyas et al. reported [30] that GCT of the larynx has been described as being malignant. The 


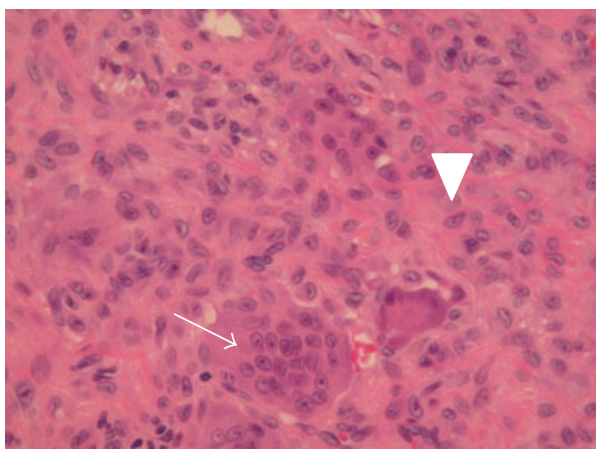

(a)

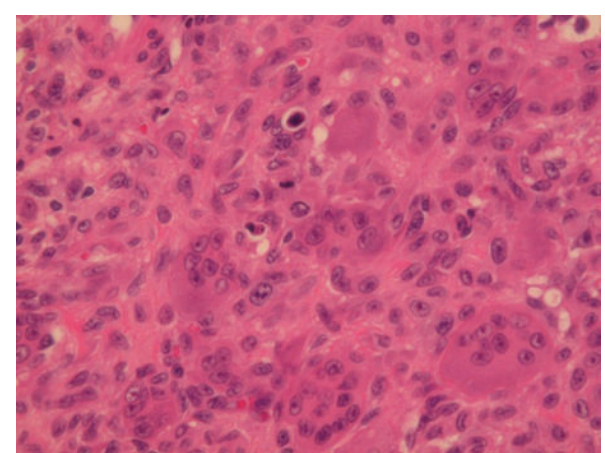

(b)

Figure 4: (a) Histological examination demonstrates that the cellular mononuclear eosinophilic stromal component (arrowhead) and multinucleated osteoclast-like giant cells (arrow) were scattered throughout the lesions in an intermediate power field. Pleomorphic giant cells are absent. (b) Mitotic figures are about 6/10 HPF by the lack of cytological atypia.

tumor appeared to arise from the soft tissue of the right vocal cord, and an osteocartilaginous origin was not documented. It is reported to have had pleomorphic histologic features. The tumor was characterized by multiple recurrences in spite of local excision and subsequent irradiation. It eventually involved the overlying skin. Although interpreted as a "metastasis," it may actually have been soft tissue seeding. The patient has had no recurrence during 1 year of followup. This case is unusual with respect to its soft-tissue origin. However, even if it is accepted as a GCT of the soft tissue of the larynx, recurrence and implantation into adjacent soft tissue did not produce an adverse clinical outcome. If comparisons are drawn with GCT of the skeleton, similar clinical courses exist $[33,34]$.

\section{Conclusion}

GCT of the larynx is an uncommon entity, with very few cases reported in the literature. GCT of the larynx should be treated with complete surgical removal and has an excellent prognosis. We performed total laryngectomy on a patient with GCTL. The patient is free of recurrence after two and a half years, but long-term observation is still required.

\section{Conflict of Interests}

The authors declare that there is no conflict of interests regarding the publication of this paper.

\section{References}

[1] K. K. Unni, Darlin's Bone Tumors: General Aspect and Data on 11087 Cases, Lippincott-Raven, Philadelphia, Pa, USA, 5th edition, 1996.

[2] A. Curilovic, G. F. Eich, and T. Stallmach, "Giant cell tumor in the skull of a 9-year-old child: immunohistochemistry to confirm a diagnosis rare for age and site," Pediatric Pathology and Laboratory Medicine, vol. 15, no. 5, pp. 769-779, 1995.

[3] M. Campanacci, N. Baldini, S. Boriani, and A. Sudanese, "Giantcell tumor of bone," Journal of Bone and Joint Surgery A, vol. 69, no. 1, pp. 106-114, 1987.
[4] E. Wessely, "Eim Fall von Equlis larynges," Monatsschr Ohrenheikd, vol. 74, pp. 158-161, 1940.

[5] F. Wustrow, Die Tumoren des Gesichsschadels, Urban \& Schwarzenberg, Munchen, Germany, 1965.

[6] O. Kleinsasser and H. Albrecht, "Die Riesenzelltumoren der Schädelbasis," Archiv für Ohren- Nasen- und Kehlkopfheilkunde, vol. 172, no. 3, pp. 246-256, 1958.

[7] S. S. Federova, "Giant cell tumor of larynx," Vestn Otorhinolaringol, vol. 4, pp. 80-81, 1951 (Russian).

[8] W. Wagemann, "Riesenzellgeshwulst in Kehlkopfraum," HNO, vol. 3, pp. 92-93, 1952.

[9] A. Perrino, “Tumore a cellule gigantic della laringe," Les Annales d'oto-laryngologie, vol. 57, pp. 140-149, 1958.

[10] P. F. Kaliteevskii and A. Korol'kova, "A case of laocalization of osteoblastclastoma in the larynx," Vestnik Otorinolaringologii, vol. 28, pp. 69-71, 1966.

[11] W. Pohl, "Uber ein Riesenzellgewachs des Kehlkopfes," Zeitschrift fur Laryngologie, Rhinologie, Otologie und ihre Grenzgebiete, vol. 47, pp. 727-729, 1968.

[12] K. Kohn, "Kehlkoopf und Luftrohre," in Spezielee pathologische Anatomie, W. Doerr, G. Seifert, and E. Uehlinger, Eds., pp. 226228, Springer, Berlin, Germany, 4th edition, 1969.

[13] H. Rudert, "Giant cell tumor of the larynx," $H N O$, vol. 19, no. 10, pp. 306-309, 1971.

[14] J. Hall-Jones, "Giant cell tumour of the larynx," Journal of Laryngology and Otology, vol. 86, no. 4, pp. 371-381, 1972.

[15] T. Goto and Y. Nakashima, "Giant cell tumor of the larynx," Otologia Fukuoka, vol. 19, no. 4, pp. 507-509, 1973.

[16] E. Kotarba and A. Niezabitowski, "Guz olbrzymiokomorkowythanek wytkaneck mickkich kitani," Otolaryngologia Polska, vol. 28, pp. 331-335, 1974.

[17] O. Ribari, G. Elemer, and A. Balint, "Laryngeal giant cell tumour," Journal of Laryngology and Otology, vol. 89, no. 8, pp. 857-861, 1975.

[18] R. Kubo, K. Katsuda, and T. Nobori, "Giant cell tumor of the larynx,” Otologia Fukuoka, vol. 22, no. 6, pp. 776-779, 1976.

[19] G. A. Tsybyme and N. I. Bogdanskaia, "OSteoblastoma of the larynx," Voprosy Onkologii, vol. 25, pp. 62-64, 1979 (Russian).

[20] M. Borghese, C. Porcaro, and C. A. Leone, "Su di un raro caso di tumore a mielopassi della laringe," L'Oto-rino-laringologia Italiana, vol. 38, pp. 157-159, 1988. 
[21] J. M. Badet, J. C. Chobaut, B. Kantelip, and A. Racle, "Giant cell tumor of the cricoid bone. Apropos of a case," Annales d'OtoLaryngologie et de Chirurgie Cervico-Faciale, vol. 109, no. 1, pp. 52-56, 1992.

[22] G. L. Murrell and H. J. Lantz, "Giant cell tumor of the larynx," Ear, Nose and Throat Journal, vol. 72, no. 5, pp. 360-361, 1993.

[23] P. C. Martin, S. A. Hoda, H. T. Pigman, and D. R. Pulitzer, "Giant cell tumor of the larynx: case report and review of the literature," Archives of Pathology and Laboratory Medicine, vol. 118, no. 8, pp. 834-837, 1994.

[24] S. Miyata, K. Kitagawa, and M. Kanou, "A case of giant-cell tumor of the thyroid cartilage," Japanese Journal of Cancer Clinics, vol. 40, pp. 519-522, 1994.

[25] J. A. Werner, D. Harms, and A. Beigel, "Giant cell tumor of the larynx: case report and review of the literature," Head and Neck, vol. 19, pp. 153-157, 1997.

[26] M. L. Hinni, "Giant cell tumor of the larynx," Annals of Otology, Rhinology and Laryngology, vol. 109, no. 1, pp. 63-66, 2000.

[27] J. A. Wieneke, F. H. Gannon, D. K. Heffner, and L. D. R. Thompson, "Giant cell tumor of the larynx: a clinicopathologic series of eight cases and a review of the literature," Modern Pathology, vol. 14, no. 12, pp. 1209-1215, 2001.

[28] K. K. Wong and H. Seikaly, "Giant cell tumour of the larynx: case report and review of the literature," Journal of Otolaryngology, vol. 33, no. 3, pp. 195-197, 2004.

[29] K. Nishimura, T. Satoh, C. Maesawa, K. Ishijima, and H. Sato, "Giant cell tumor of the larynx: a case report and review of the literature," The American Journal of Otolaryngology-Head and Neck Medicine and Surgery, vol. 28, no. 6, pp. 436-440, 2007.

[30] A. Coyas, O. T. Anastassiades, and I. Kyriakos, "Malignant giant cell tumour of the larynx," Journal of Laryngology and Otology, vol. 88, no. 8, pp. 799-803, 1974.

[31] R. S. Bell, A. R. Harwood, S. B. Goodman, and V. L. Fornasier, "Supervoltage radiotherapy in the treatment of difficult giant cell tumors of bone," Clinical Orthopaedics and Related Research, vol. 174, pp. 208-216, 1983.

[32] M. Wülling, C. Engels, N. Jesse, M. Werner, G. Delling, and E. Kaiser, "The nature of giant cell tumor of bone," Journal of Cancer Research and Clinical Oncology, vol. 127, no. 8, pp. 467474, 2001.

[33] D. C. Dahlin, R. E. Cupps, and E. W. Johnson Jr., "Giant-cell tumor: a study of 195 cases," Cancer, vol. 25, no. 5, pp. 1061-1070, 1970.

[34] A. G. Huvos, "Giant cell tumor of bone," in Bone Tumors; Diagnosis, Treatment, and Prognosis, pp. 429-468, WB Saunders, Philadelphia, Pa, USA, 1991. 


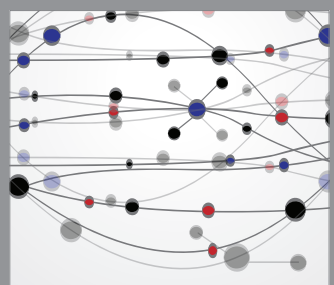

The Scientific World Journal
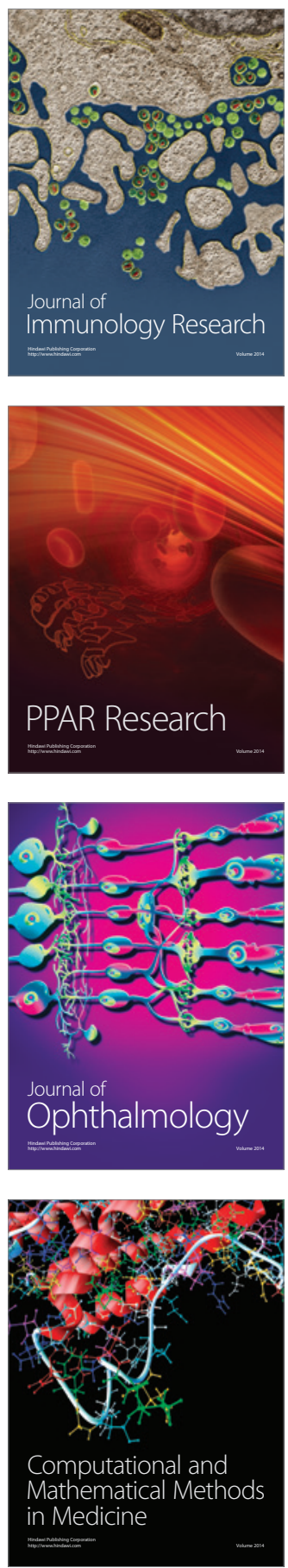

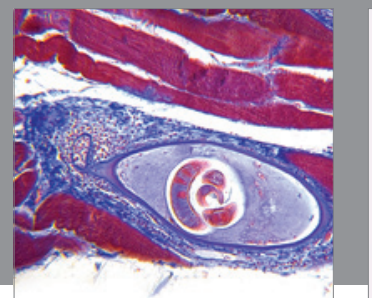

Gastroenterology

Research and Practice
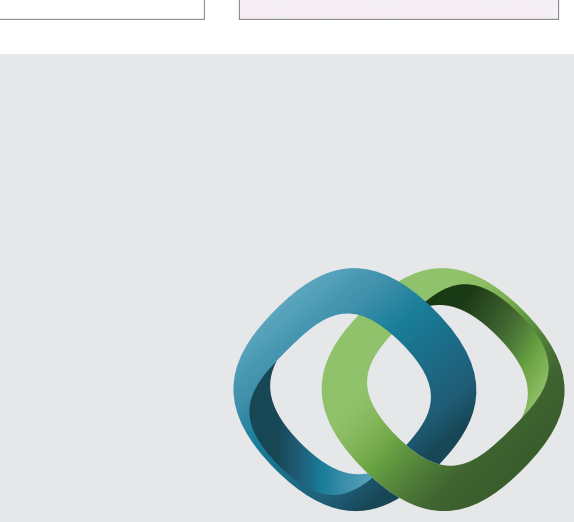

\section{Hindawi}

Submit your manuscripts at

http://www.hindawi.com
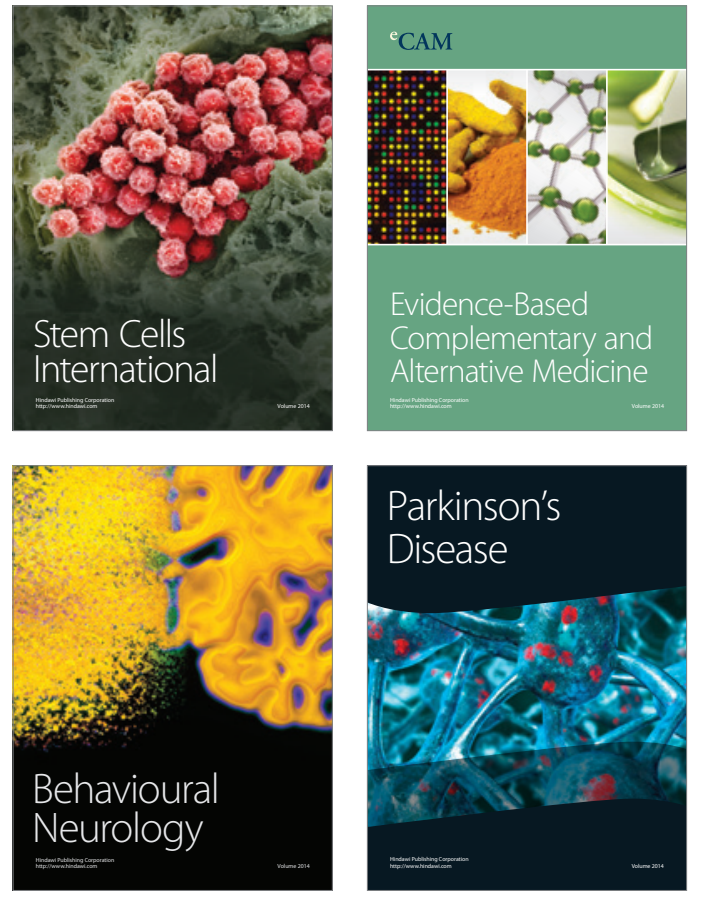
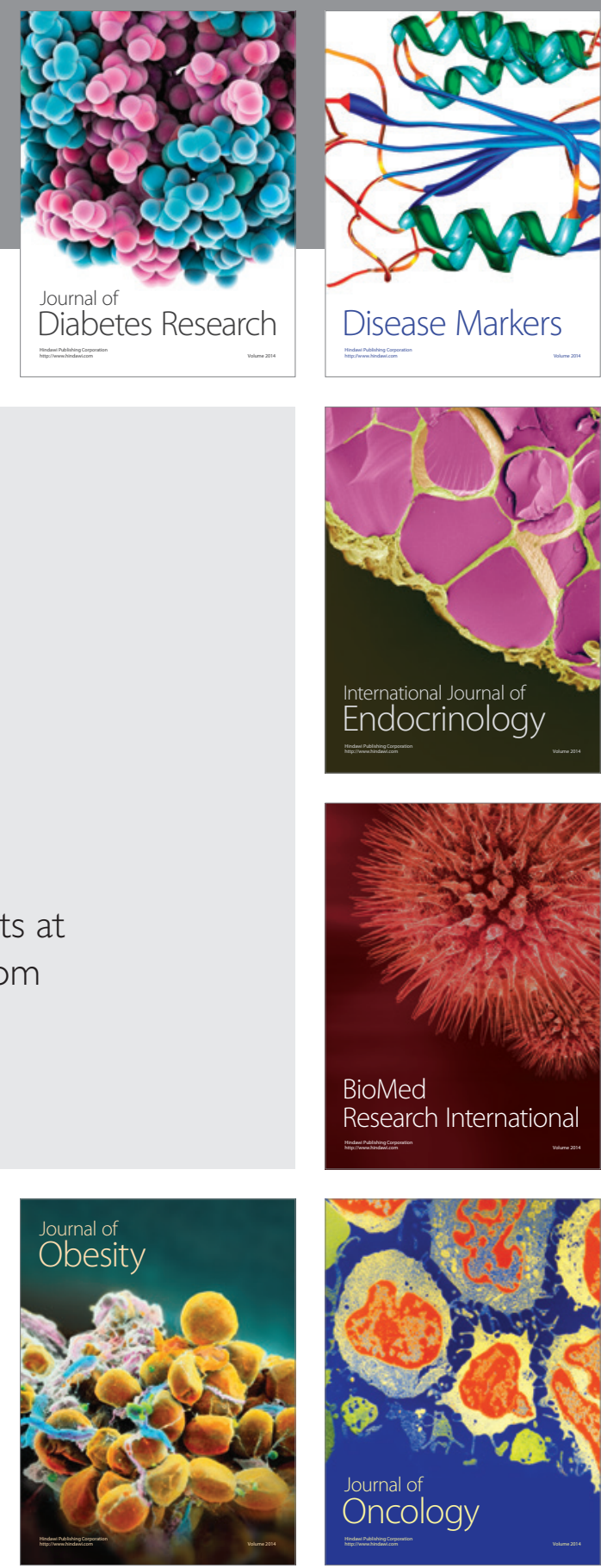

Disease Markers
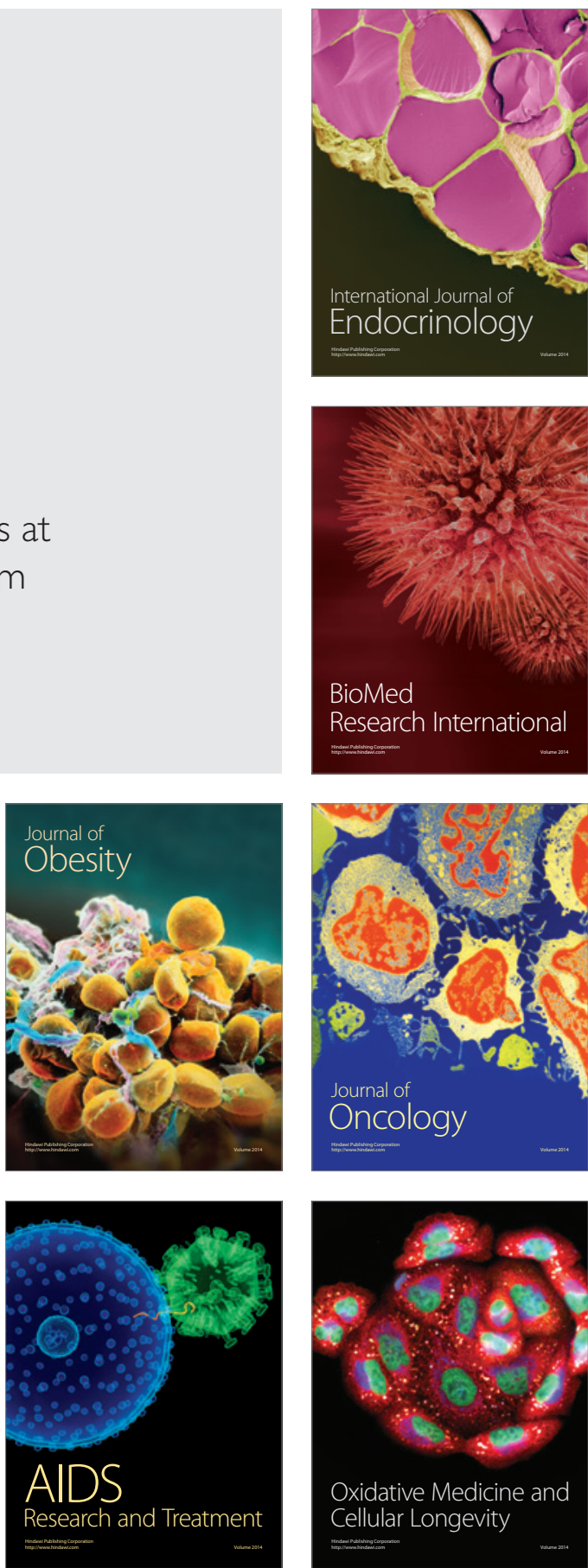